\title{
Effects of co-occurring disorders on employment outcomes in a multisite randomized study of supported employment for people with severe mental illness
}

Judith A. Cook, PhD; ${ }^{1 *}$ Lisa A. Razzano, PhD; ${ }^{1}$ Jane K. Burke-Miller, MS; ${ }^{1}$ Crystal R. Blyler, PhD; ${ }^{2}$ H. Stephen Leff, PhD $;{ }^{3}$ Kim T. Mueser, PhD; ${ }^{4}$ Paul B. Gold, PhD $;{ }^{5}$ Richard W. Goldberg, PhD; ${ }^{6}$ Michael S. Shafer, PhD; Steven J. Onken, PhD; ${ }^{8}$ William R. McFarlane, MD; ${ }^{9}$ Kate Donegan, EdD; ${ }^{10}$ Martha Ann Carey, PhD; ${ }^{11}$ Caroline Kaufmann, PhD; ${ }^{12}$ Dennis D. Grey, BA ${ }^{1}$

${ }^{1}$ University of Illinois at Chicago, Chicago, IL; ${ }^{2}$ Center for Mental Health Services, Rockville, MD; ${ }^{3}$ Human Services Research Institute, Cambridge, MA; ${ }^{4}$ Dartmouth University, Concord, $\mathrm{NH} ;{ }^{5}$ Medical University of South Carolina, Charleston, SC; ${ }^{6}$ University of Maryland, Baltimore, $M D ;{ }^{7}$ Arizona State University, Phoenix, AZ; ${ }^{8}$ University of Hawaii at Manoa, Honolulu, HI; ${ }^{9}$ Maine Medical Center, Portland, ME; ${ }^{10}$ The Matrix Center at Horizon House, Inc, Philadelphia, PA; ${ }^{11}$ Azusa Pacific University, Azusa, CA; ${ }^{12}$ Consumer Research and Advocacy, Clearwater, FL

\begin{abstract}
Effects of co-occurring disorders on work outcomes were explored among individuals with severe mental illness who were participating in a multisite randomized study of supported employment. At seven sites, 1,273 people were randomly assigned to an experimental supported employment program or a control condition and followed for 2 years. Multivariate regression analysis examined work outcomes including earnings, hours worked, and competitive employment, as well as whether psychiatric disability was disclosed to coworkers and supervisors. Individuals with any comorbidity had lower earnings and were less likely to work competitively. Those with physical comorbidities had lower earnings, worked fewer hours, and were less likely to work competitively. Disclosure was more likely among those with both cognitive and physical comorbidities, as well as those with learning disabilities. Competitive employment was less likely among those with intellectual disability, visual impairment, and human immunodeficiency virus/acquired immunodeficiency syndrome. The experimental condition was positively related to all outcomes except disclosure. The results suggest that, with some exceptions, comorbidities affect employment outcomes, requiring tailored services and supports to promote vocational success.
\end{abstract}

Key words: comorbidities, co-occuring disorders, employment, evidence-based practice, mental illness, psychiatric disability, recovery, substance use, supported employment, vocational rehabilitation.

\section{INTRODUCTION}

Considerable research evidence points to low rates of labor force participation among individuals with psychiatric disabilities. Analysis of data from a national household survey revealed that more than three-quarters (77\%) of the general working-age population are employed in a given year, while less than one-fifth (17\%) of those with severe mental health conditions are working [1]. Supported employment, an evidence-based practice (EBP) for enhancing employment outcomes among people with severe

Abbreviations: ADHD $=$ attention deficit hyperactivity disorder, AIDS = acquired immunodeficiency syndrome, CMHS = Center for Mental Health Services, EBP = evidence-based practice, EIDP = Employment Intervention Demonstration Program, HIV = human immunodeficiency virus, SAMHSA = Substance Abuse and Mental Health Services Administration, SCI = spinal cord injury, TBI = traumatic brain injury.

* Address all correspondence to Dr. Judith A. Cook, Department of Psychiatry, University of Illinois at Chicago, 1601 West Taylor St, 4th Floor M/C 912, Chicago, IL 60612; 312355-3921; fax: 312-355-4189. Email: cook@ripco.com

DOI: 10.1682/JRRD.2006.07.0079 
mental illness, is available [2-3]. However, many outpatients have co-occurring physical illnesses, chronic medical conditions, and disabilities that also impair vocational performance and may affect their ability to benefit from supported employment services. This article explores associations between supported employment and work outcomes as influenced by co-occurring disorders.

A growing body of literature indicates the high prevalence of medical disorders among people with severe mental illness, including cardiovascular disease, tuberculosis, and diseases of the lungs, kidneys, and digestive tract [4-5]. Dixon et al. surveyed 719 people with schizophrenia and found that the majority reported at least one medical problem, most often high blood pressure, poor vision, or dental problems [6]. Dickey et al. reviewed 11,185 adult Medicaid beneficiaries treated for severe mental illness and found that 56 percent had one and 26 percent had more than one of the following: diabetes, hypertension, heart disease, asthma, gastrointestinal disorders, infections of the skin and subcutaneous tissue, malignant neoplasms, and acute respiratory disorders [7]. Similarly, Jones et al. analyzed Medicaid claims data for 147 individuals with severe mental illness and found that 74 percent had one diagnosis of chronic health problems, while 50 percent had two or more diagnoses [8]. Sokal et al. studied 200 psychiatric outpatients with schizophrenia and affective disorders and found that they had significantly elevated odds of diabetes, lung diseases, and liver problems compared with matched subsets of individuals from the general population [9]. All of these medical conditions may be related to impaired physical and social role functioning and lowered rates of labor force participation.

Substance use is perhaps the most frequently identified co-occurring disorder among psychiatric outpatients. In 2002, out of 17.5 million adults (aged 18 and older) with serious mental illness, 4 million, or 23 percent, were also dependent on or abused alcohol or illicit drugs [10]. Among all U.S. adults aged 18 or older, 12.2 percent (4 million) had both serious mental illness and a substance use disorder [10]. However, findings are also inconsistent regarding the relationship of substance use to employment outcomes in this population [11-12]. While some studies suggest that substance use has deleterious effects on employment outcomes [13-15], others have found that clients with this comorbidity do as well as or better in vocational programs than those without comorbidity [16-19].
Attention deficit hyperactivity disorder (ADHD), which commonly co-occurs with other psychiatric disorders, is associated with unemployment and other work role impairments [20]. Traumatic brain injury (TBI) is also often accompanied by mood and other psychiatric disorders, and this co-occurrence has been associated with poor vocational outcomes [21]. Individuals living with human immunodeficiency virus/acquired immunodeficiency syndrome (HIV/AIDS) experience high unemployment [22] and encounter a number of challenges to workforce reentry, including a need for vocational training, substance abuse treatment, and help with co-occurring psychiatric disorders [23]. Individuals with co-occurring intellectual disability and mental illness encounter significant barriers to competitive employment that can be effectively addressed with supported employment [24]. In a review of major studies of individuals with psychiatric disabilities, McGurk and Mueser conclude that cognitive impairments are associated with poorer vocational functioning [25]. Finally, in addition to affecting employment status and work outcomes, cooccurring disorders may increase the chances that an individual's health and level of impairment are scrutinized by others, leading to a greater likelihood of disclosure of psychiatric status [26-27]. Disclosure may elicit both positive and negative reactions from employers and coworkers [28-31].

This study tested three hypotheses. First, we hypothesized that individuals with mental illness and cooccurring conditions would have lower earnings, work fewer hours, and be less likely to work competitively in a controlled study of supported employment. Second, we hypothesized that those receiving experimental supported employment services would fare better on these outcomes than controls, despite co-occurring medical conditions and impairments. And third, we hypothesized that those with co-occurring conditions would be more likely to disclose their psychiatric disability to coworkers and supervisors than those without comorbidities.

\section{METHODS}

\section{Multisite Study Background}

The Employment Intervention Demonstration Program (EIDP) began in 1995 with the selection of eight study sites in Maryland, Connecticut, South Carolina, Pennsylvania, Arizona, Massachusetts, Maine, and Texas [32]. A coordinating center at the Department of Psychiatry, University of 
Illinois at Chicago, led the effort in collaboration with the Human Services Research Institute in Cambridge, Massachusetts. Under a cooperative agreement, the coordinating center led the development of a common protocol and standardized data collection techniques, monitored data quality, assembled multisite databases, and conducted statistical analyses as planned by the principal investigators, consumer researchers, and Federal personnel. All sites and the coordinating center received approval of human subjects protection and confidentiality safeguards required for recruitment, written informed consent, and data management, as determined by their respective organizations' institutional review boards.

\section{Study Participants}

The eligibility criteria for study participation were diagnosis, duration, and disability requirements for severe and persistent mental illness as defined by the Federal Center for Mental Health Services (CMHS); aged 18 years or older; desire for paid employment; and written informed consent [33]. At all sites, participants were recruited from clinical populations by provider referral, self- or family-referral, and word-of-mouth referral. Newspaper advertisements were also used at the Massachusetts site. The eligible pool of study participants numbered 10,653; out of this group, 2,883 were contacted about participation (numbers exclude the Massachusetts site, which was unable to provide this information). Across all sites (including Massachusetts), 1,750 consented to participate in the study, 1,655 completed the first interview, and 1,648 were randomized. The reasons that some who agreed to participate were never randomized included subsequent patient refusal, ineligibility (based on age, willingness to work, or lack of informed consent), and individuals lost to follow-up.

Of the 1,648 who were randomized, 375 were excluded from this analysis because (1) participants were employed at baseline (this included all 182 Pennsylvania participants, given that this site's intervention focused on clients who were already working, as well as 28 additional participants from other sites who were later determined to have been employed at study entry), (2) participants were involved in a second control condition consisting of transitional employment services in Connecticut (which was the only site with a three-arm trial), and (3) no vocational outcome data were available for 100 subjects. No participants were excluded for any other reason, given the "intent to treat" design of the demonstration.
Study recruitment occurred between February 1996 and May 2000, and participants received monetary stipends for each interview (amounts varied by site according to the local economy and over time from $\$ 10$ to $\$ 20$ ). The 1,273 subjects in the analysis were distributed as follows: Maine $(n=108)$, Connecticut $(n=133)$, Massachusetts $(n=166)$, Maryland ( $n=197)$, South Carolina $(n=$ $142)$, Texas $(n=233)$, and Arizona $(n=294)$.

\section{Data Collection Procedures}

Staff at all sites attended a 2-day intensive train-thetrainer event conducted in December 1995 by the coordinating center in Baltimore, Maryland, at which data collection protocols were taught and practiced, including the chart review protocol for collecting comorbidity data used in this analysis. Interview assessments with EIDP participants elicited information regarding demographic characteristics, employment history, and other relevant information at the time of study enrollment (baseline) and at 6-month follow-up intervals for 24 months. Vocational data were collected weekly and included job tenure, hours worked, earnings, job characteristics, and workplace disclosure of psychiatric disability.

\section{Experimental Supported Employment Models Tested}

The study was designed as a randomized implementation effectiveness trial [34], and sites tested different models of supported employment and compared them with a variety of different control conditions. The experimental condition was always a form of enhanced best-practice supported employment [35] that was compared with either services as usual or an "unenhanced" version of the experimental model (see the next section "Control Conditions"). The Maryland, Connecticut, and South Carolina sites tested the Individual Placement and Support model, in which multidisciplinary provider teams engage in minimal prevocational assessment, rapid job search, placement into competitive jobs, and provision of training and ongoing follow-up supports [36]. The Massachusetts site used the Program of Assertive Community Treatment vocational model with services provided exclusively in the community through a mobile team comprising psychiatrists, nurses, case managers, and vocational specialists who collaboratively place clients in competitive employment and provide job training and continuous employment support [37]. The Texas, Maine, and Arizona sites used models developed especially for the EIDP. In Texas, the model included supported employment services with social 
network enhancements that were specifically designed to help individuals create more balanced and reciprocal interpersonal networks to bolster work efforts. In Maine, the model used family-aided assertive community treatment teams whose vocational staff worked with an employer consortium of the area's major businesses to develop job opportunities, workplace supports, and reasonable accommodations. In Arizona, the model consisted of an integrated treatment team comprising psychiatrists, case managers, rehabilitation counselors, employment specialists, job developers, and benefits specialists, emphasizing rapid job placement and ongoing support for job retention and career advancement. Further details about the models tested at each site are available at the EIDP study Web site, $<$ http://www.psych.uic.edu/eidp/> .

\section{Control Conditions}

Ethical considerations barred a "no treatment" control condition, since participants who entered the study expressed a willingness to work. Sites elected to use one of two types of control conditions: (1) services-as-usual or (2) a comparison condition that was lacking the "active ingredient" being-tested in the site's experimental condition. The services-as-usual control condition, used in Arizona, Connecticut, Maryland, and South Carolina, was defined by whatever services were typically available in the local community. In Texas and Maine, comparison conditions consisted of "unenhanced" versions of each site's experimental condition, eliminating the social network component offered with supported employment in Texas, and the employer consortium activities in Maine. At the final site (Massachusetts) the Clubhouse Model was used, in which transitional employment placements (defined as time-limited positions reserved for people with a mental illness) were used along with supported employment [38-39]. Given that some control conditions involved delivery of employment services, the measured effect of the experimental condition may be weaker than what might have been observed had all the conditions been true notreatment control conditions.

\section{Model Fidelity}

As a manipulation check of fidelity among the experimental versus control conditions [40-41], we compared the amounts and types of vocational services received by the two groups. Results indicated that experimental group participants received significantly greater amounts of each of 10 different types of supported employment services
( $p<0.001$ ), including (1) on-site job support, (2) collaboration with employers, (3) job development and placement, (4) off-site job skills training and education, (5) offsite vocational counseling, (6) vocational assessment and evaluation, (7) vocational support groups, (8) vocational treatment planning/career counseling, (9) job-related collaboration with family and friends, and (10) job-related transportation [3]. However, no significant difference existed between the groups in their likelihood of receiving clinical services.

\section{Dependent Variables}

We assessed vocational outcomes using several different characteristics of participants' employment during the study as dependent variables, including total earnings, hours worked, achievement of competitive employment, and disclosure of psychiatric disability at the workplace. The first outcome assesses the participant's economic productivity. The second measures work productivity. The third evaluates participants' ability to vie with nondisabled workers for a job in a competitive labor market that is not reserved for individuals with disabilities. Finally, the fourth outcome assesses the potential for enhanced scrutiny associated with co-occurring conditions, which might lead to disclosure of mental illness to coworkers and supervisors.

\section{Independent Variables}

The first independent variable was study condition. All the models in the experimental condition followed criteria established at the study's outset for EBP supported employment: (1) integrated services delivered by a multidisciplinary team that met three or more times a week to plan and coordinate employment interventions with case management and psychiatric treatment; (2) placement into jobs paying at least minimum wage in regular, socially integrated community settings not reserved for individuals with disabilities and held by clients rather than provider agencies; (3) development of jobs tailored to participants' career preferences; (4) a job-search process that began immediately upon program entry and moved as quickly as a participant desired; and (5) provision of ongoing vocational supports freely available throughout the entire study period rather than gradual withdrawal of support following successful employment.

The second independent variable was co-occurring chronic and acute medical conditions and illnesses, as well as physical and cognitive impairments. Chart review at 
baseline identified comorbidities as defined by diagnoses recorded in study participants' case files, including but not limited to Diagnostic and Statistical Manual of Mental Disorders-4th Edition diagnoses [42]. The abstraction procedure involved detailed review of participants' case files at study entry by researchers who were trained for this purpose with the use of a uniform protocol at each study site. The abstraction protocol called the researchers' attention to 12 specific conditions that were expected to occur with some frequency in this population, given prior research (intellectual impairment, head injury, spinal cord injury [SCI], autism, cerebral palsy, seizure disorder, hearing impairment, visual impairment, learning disability, speech/language impairment, HIV/AIDS, ADHD). Space was also provided for the researchers to record additional diagnoses using an "other" category; these "other" diagnoses were then classified and coded by staff from the coordinating center. This process yielded a number of conditions, including cognitive impairments (e.g., intellectual disability, learning disability), communication impairments (e.g., hearing impairment, visual impairment), physical impairments (e.g., SCI, cerebral palsy), chronic illnesses (e.g., diabetes, arthritis), and acute illnesses (e.g., gunshot wound, broken bone). To monitor quality throughout the 4-year data collection period, the coordinating center computed information regarding comorbidities and all principal investigators and the study steering committee reviewed these computations at biannual meetings to check for unexplainable site variations and address any unusual patterns. Prior to the statistical analysis, an expert panel of three disability experts, one internal to the study and two external (i.e., the chair of the Department of Disability Studies at a large state university and a senior faculty member from the same department) coded all diagnoses and grouped them as conditions that primarily affected either cognitive or physical functioning, using discussion and consensus to resolve coding of diagnoses on which they disagreed. Once diagnoses were coded and classified, their existence was operationalized in the analysis as (1) any comorbidities versus none; (2) number of different comorbidities; (3) whether the individual had comorbidities associated with cognitive impairment, physical impairment, or both (with substance abuse/dependence coded separately from these three); and (4) discrete comorbid conditions.

\section{Control Variables}

Variables shown to influence work outcomes in prior studies of individuals with severe mental illness included gender (coded as male), race/ethnicity (African American, Hispanic/Latino, Caucasian, other), education (high school graduate), and age at baseline [43].

\section{Follow-Up Rates and Attrition Analysis}

As reported previously, of the 1,273 participants at baseline, 824 (65\%) completed all five interviews, 173 (14\%) completed four interviews, 122 (9\%) completed three, 111 (9\%) completed two, and the remaining 43 (3\%) completed one $[3,44]$. In analyses comparing model covariates by study condition, those who completed all five interviews versus those who did not, no significant differences by attrition existed except for two variables: men were overrepresented among noncompleters and noncompleters were younger than completers. Both variables were controlled in all subsequent analyses.

\section{Statistical Analysis}

We used ordinary least-squares regression for the multivariate analysis of interval-level dependent variables and logistic regression for dichotomous outcomes. All analyses were conducted with SPSS version 12.0 (SPSS Inc, Chicago, Illinois). The multivariate model tested included comorbidity measured in four ways, as described previously, study condition (experimental vs control), and control variables. Additionally, all models controlled for study site.

\section{RESULTS}

\section{Participant Demographic and Work History Characteristics}

Almost half (49\%) of all participants had a diagnosis of either schizophrenia (31\%) or schizoaffective disorder (18\%). Another 21 percent had a primary diagnosis of major depression, 16 percent were diagnosed with bipolar disorder, and 2 percent with dysthmymia. The remaining 12 percent had a variety of diagnoses with no one diagnosis affecting more than 1 percent of participants, including posttraumatic stress disorder, anxiety disorders, delusional disorder, and obsessive-compulsive disorder. At baseline, 50 percent were living independently and 19 percent had coresident children under 18 years of age. On average, participants had six psychiatric hospitalizations prior to baseline, with an average of 13 months spent hospitalized in their lifetimes. Half had been hospitalized within 14 months of baseline. Almost all (96\%) reported having a prescription for psychiatric medications. Of all participants, 
34 percent had less than a high school education, and another 30 percent had no higher than a high school education. Fewer than two-thirds (64\%) had held some form of paid employment in the 5 years prior to the study. Of all participants, 53 percent were male and 50 percent were Caucasian, 30 percent African American, 14 percent Hispanic/Latino, and 6 percent mixed or other race/ethnicity. Average and median age were 38 years at baseline.

\section{Co-Occurring Conditions}

Table 1 presents the co-occurring conditions abstracted from case files at study baseline. More than half (59.9\%) the study participants were reported to have one or more comorbidities. On average, participants had $0.99 \pm 1.17$ standard deviation conditions, and 25 percent had two or more comorbidities, with a range from 0 to 12 . Of all participants, 25 percent $(n=313)$ had a condition

Table 1.

Comorbid condition at baseline by study condition and total sample.

\begin{tabular}{|c|c|c|c|}
\hline Comorbid Condition & $\begin{array}{l}\text { Control } \\
(n=623)\end{array}$ & $\begin{array}{c}\text { Experimental } \\
(n=650)\end{array}$ & $\begin{array}{c}\text { Total } \\
(N=1,273)\end{array}$ \\
\hline \multicolumn{4}{|l|}{ Presence/Absence, $n$ (\%) } \\
\hline No Comorbid Condition & $252(40.4)$ & 258 (39.7) & $510(40.1)$ \\
\hline \multicolumn{4}{|c|}{ Intensity of Comorbid Conditions (total No. reported) } \\
\hline 0 & $252(40.4)$ & $258(39.7)$ & $510(40.1)$ \\
\hline 2 & $100(16.1)$ & $96(14.8)$ & 196 (15.4) \\
\hline 3 & $33(5.3)$ & $45(6.9)$ & $78(6.1)$ \\
\hline 4 & $17(2.7)$ & $13(2.0)$ & $30(2.4)$ \\
\hline $5+$ & $2(0.3)$ & $9(1.4)$ & $11(0.8)$ \\
\hline \multicolumn{4}{|l|}{ Cognitive } \\
\hline Intellectual Disability & $83(13.2)$ & $75(11.5)$ & 157 (12.3) \\
\hline Head Injury & $67(10.8)$ & $75(11.5)$ & $142(11.2)$ \\
\hline Learning Disability & $36(5.8)$ & $34(5.2)$ & $70(5.5)$ \\
\hline Attention Deficit Hyperactivity Disorder & $19(3.0)$ & $24(3.7)$ & $43(3.4)$ \\
\hline Autism & $1(0.2)$ & $1(0.2)$ & $2(0.02)$ \\
\hline \multicolumn{4}{|l|}{ Physical } \\
\hline Visual Impairment & $55(8.8)^{\dagger}$ & $79(12.2)^{\dagger}$ & $134(10.5)$ \\
\hline Seizure Disorder & $35(5.6)$ & $45(6.9)$ & $80(6.3)$ \\
\hline Substance Abuse/Dependence & $231(35.5)$ & $220(35.3)$ & $451(35.4)$ \\
\hline \multicolumn{4}{|c|}{$\begin{array}{l}{ }^{*} \text { Percentages do not add to } 100 \text { since respondents could have more than one condition. } \\
{ }^{\dagger} \chi^{2}(1)=3.58, p=0.036 \text {. } \\
{ }^{\dagger} \text { For example, diabetes, heart disease, sickle cell anemia, gunshot wound, arthritis, or back injury. } \\
\text { Max = maximum, min = minimum. }\end{array}$} \\
\hline
\end{tabular}


associated with cognitive impairment: 12.3 percent $(n=$ 157) had intellectual disability (e.g., low or borderline intelligence quotient), 11.2 percent $(n=142)$ head injuries, 5.5 percent $(n=70)$ learning disabilities, 3.4 percent $(n=$ 43) ADHD, and 0.02 percent $(n=2)$ autism. Almost a quarter $(24 \%, n=300)$ had conditions associated with physical impairments: 10.5 percent $(n=134)$ visual impairment, 6.3 percent $(n=80)$ seizure disorder, 3.4 percent $(n=43)$ SCI, 3.0 percent $(n=38)$ HIV positive, 2.4 percent $(n=30)$ speech/language impairment, 2.0 percent $(n=26)$ chronic or acute medical condition (e.g., diabetes, heart disease, sickle cell, gunshot wound, arthritis, or back injury), 2.0 percent $(n=25)$ hearing impairment, and 0.6 percent $(n=7)$ cerebral palsy. Finally, 35.4 percent $(n=451)$ had a diagnosis of drug or alcohol abuse or dependence. No statistically significant differences existed in occurrence, intensity, or type of co-occurring conditions between study conditions except that the experimental condition had a higher prevalence of visual impairments $(12.2 \%, n=79)$ than the control condition $(8.8 \%, n=55)$.

\section{Employment Outcomes}

Table 2 shows the employment outcomes that indicated significant differences by study condition on three of four outcomes. The first was earnings, with experimental condition participants averaging significantly greater amounts $(\$ 2,882)$ over the 24 -month follow-up period than control condition participants $(\$ 2,262)$. Next, average hours worked during the 24-month follow-up period were significantly greater for experimental participants (515 hours) than controls (409 hours). Among all participants, a significantly higher proportion of experimental group participants obtained competitive employment (39\%) than did controls (29\%). Finally, among only those who worked during the study, no differences by study condition existed regarding disclosure of psychiatric disability at the workplace: disclosure occurred for 75 percent of experimental and 71 percent of control group participants.

\section{Multivariate Analyses}

Table 3 presents the results of multivariate analyses of effects of presence, intensity, type, and specific diagnosis of comorbidity on each of the four vocational outcomes. In the first set of columns predicting total earnings, those with any comorbidity had significantly lower total earnings, as did those with comorbidities affecting physical functioning. In addition, study condition was significant in

Table 2.

Employment outcomes over 24 months by study condition and total sample.

\begin{tabular}{|c|c|c|c|}
\hline Employment Outcomes & $\begin{array}{l}\text { Control } \\
(n=623)\end{array}$ & $\begin{array}{l}\text { Experimental } \\
\qquad(n=650)\end{array}$ & $\begin{array}{c}\text { Total } \\
(N=1,273)\end{array}$ \\
\hline \multicolumn{4}{|l|}{ Total Earnings (\$) } \\
\hline Mean \pm Standard Deviation (SD) & $2,262 \pm 4,579^{*}$ & $2,882 \pm 5,191^{*}$ & $2,577 \pm 4,908$ \\
\hline Median (mode) & $173(0)$ & $538(0)$ & $331(0)$ \\
\hline Range (min-max) & $39,894(0-39,894)$ & $45,611(0-45,611)$ & $45,611(0-45,611)$ \\
\hline \multicolumn{4}{|l|}{ Total Hours Worked in 24 Months } \\
\hline Mean \pm SD & $409 \pm 766^{*}$ & $515 \pm 867^{*}$ & $463 \pm 821$ \\
\hline Median (mode) & $37(0)$ & $111(0)$ & $75(0)$ \\
\hline Range (min-max) & $5,336(0-5,336)$ & $6,556(0-6,556)$ & $6,556(0-6,556)$ \\
\hline \multicolumn{4}{|c|}{ Competitive Employment in 24 Months } \\
\hline Mean \pm SD & $0.29 \pm 0.45^{\dagger}$ & $0.39 \pm 0.49^{\dagger}$ & $0.34 \pm 0.47$ \\
\hline Median (mode) & $0(0)$ & $0(0)$ & $0(0)$ \\
\hline Range (min-max) & $1(0-1)$ & $1(0-1)$ & $1(0-1)$ \\
\hline \multicolumn{4}{|c|}{$\begin{array}{l}\text { Disclosure of Psychiatric Disability Ever, } \\
\text { Among Employed Only }\end{array}$} \\
\hline Mean \pm SD & $0.71 \pm 0.46(\mathrm{NS})$ & $0.75 \pm 0.43(\mathrm{NS})$ & $0.73 \pm 0.44$ \\
\hline Median (mode) & $1(1)$ & $1(1)$ & $1(1)$ \\
\hline Range (min-max) & $1(0-1)$ & $1(0-1)$ & $1(0-1)$ \\
\hline \multicolumn{4}{|c|}{$\begin{array}{l}{ }^{*} p<0.05 . \\
{ }^{\dagger} p<0.001 . \\
\text { Max = maximum, min = minimum, NS = not significant. }\end{array}$} \\
\hline
\end{tabular}


JRRD, Volume 44, Number 6, 2007

Table 3.

Results of four multivariate analyses showing effects of study condition and comorbidity (measured separately by presence, number, type, and specific condition) on four employment outcomes, controlling for gender, education, race/ethnicity, age, and study site $(N=1,273)$.

\begin{tabular}{|c|c|c|c|c|c|c|c|c|}
\hline \multirow[t]{3}{*}{ Measure of Comorbidity } & \multicolumn{2}{|c|}{ Total Earnings } & \multicolumn{2}{|c|}{ Total Hours Worked } & \multicolumn{2}{|c|}{ Competitive Employment } & \multirow{2}{*}{\multicolumn{2}{|c|}{$\begin{array}{c}\begin{array}{c}\text { Workplace Disclosure } \\
\text { of Psychiatric Disability } \\
\text { (among those ever } \\
\text { employed) }\end{array} \\
\begin{array}{c}\text { LR Odds Ratio } \\
\text { and Significance }\end{array}\end{array}$}} \\
\hline & \multicolumn{2}{|c|}{$\begin{array}{c}\text { OLS Standardized } \\
\text { Coefficient and Significance }\end{array}$} & \multicolumn{2}{|c|}{$\begin{array}{l}\text { OLS Standardized } \\
\text { Coefficient and Significance }\end{array}$} & \multicolumn{2}{|c|}{$\begin{array}{l}\text { LR Odds Ratio } \\
\text { and Significance }\end{array}$} & & \\
\hline & Comorbidity & E vs C & Comorbidity & E vs C & Comorbidity & E vs C & Comorbidity & E vs C \\
\hline Any Comorbidity & $-0.06^{*}$ & $0.06^{*}$ & -0.05 & $0.07^{*}$ & $0.76^{*}$ & $1.70^{\dagger}$ & 1.14 & 1.29 \\
\hline No. of Comorbidities & $-0.05^{\ddagger}$ & $0.06^{*}$ & -0.04 & $0.07^{*}$ & $0.90^{\ddagger}$ & $1.70^{\dagger}$ & $1.18^{\ddagger}$ & 1.30 \\
\hline \multicolumn{9}{|l|}{ Type of Comorbidity } \\
\hline Physical Only & $-0.06^{*}$ & $-0.06^{*}$ & $-0.06^{*}$ & $0.07^{*}$ & $0.48^{\S}$ & $1.72^{\dagger}$ & 1.38 & 1.31 \\
\hline Cognitive Only & -0.02 & - & -0.01 & - & 0.82 & - & 1.45 & - \\
\hline Both Cognitive \& Physical & -0.03 & - & -0.02 & - & 0.70 & - & $2.04^{*}$ & - \\
\hline Substance Abuse & -0.05 & - & $-0.05^{\ddagger}$ & - & 1.12 & - & 0.82 & - \\
\hline \multicolumn{9}{|l|}{ Specific Condition } \\
\hline Substance Abuse/Dependence & $-0.06^{\ddagger}$ & $0.06^{*}$ & $-0.06^{\ddagger}$ & $0.07^{*}$ & 1.09 & $1.71^{\dagger}$ & 0.85 & $1.35^{\ddagger}$ \\
\hline Intellectual Disability & -0.05 & - & -0.05 & - & $0.62^{*}$ & - & 1.66 & - \\
\hline Head Injury & 0.03 & - & 0.04 & - & 1.21 & - & 0.92 & - \\
\hline Learning Disability & -0.02 & - & -0.01 & - & 0.92 & - & $3.46^{*}$ & - \\
\hline Attention Deficit Hyperactivity Disorder & 0.03 & - & 0.03 & - & 1.13 & - & 0.74 & - \\
\hline Visual Impairment & -0.05 & - & $-0.06^{\ddagger}$ & - & $0.53^{*}$ & - & 1.56 & - \\
\hline Seizure Disorders & 0.03 & - & 0.03 & - & 1.06 & - & 1.02 & - \\
\hline Spinal Cord Injury & 0.01 & - & 0.02 & - & 0.64 & - & 1.13 & - \\
\hline Human Immunodeficiency Virus Positive & -0.02 & - & -0.03 & - & $0.33^{*}$ & - & 3.61 & - \\
\hline Speech/Language Impairment & -0.03 & - & -0.03 & - & 0.45 & - & 1.70 & - \\
\hline Chronic or Acute Medical Condition & -0.04 & - & -0.03 & - & $2.23^{*}$ & - & 0.68 & - \\
\hline Hearing Impairment & 0.01 & - & 0.01 & - & 0.80 & - & 0.59 & - \\
\hline Cerebral Palsy & 0.01 & - & 0.02 & - & 4.00 & - & 0.01 & - \\
\hline \multicolumn{9}{|l|}{$\begin{array}{l}{ }^{*} p<0.05 . \\
{ }^{\dagger} p<0.001 . \\
{ }^{\dagger} p<0.10 . \\
{ }^{{ }^{\dagger} p}<0.01 .\end{array}$} \\
\hline
\end{tabular}

each of the four models predicting total earnings, with experimental condition participants earning significantly more money than controls.

In the second set of columns predicting total hours worked, those with comorbidities affecting physical functioning worked fewer hours during the follow-up period than did those with other or no comorbidities. Once again, study condition was significant in all four models, with experimental group participants working a greater number of hours than controls.

The third set of columns present the results of models predicting whether subjects achieved competitive employment during the study. Those with any comorbidity were only 76 percent as likely to work competitively as those with no comorbidities. In addition, those with comorbidi- ties affecting physical functioning were less than half as likely to hold a competitive job as those with other or no comorbidities. Regarding specific conditions, individuals with intellectual disability were less than two-thirds as likely to work competitively, those with visual impairment were about half as likely, and those with HIV/AIDS were only one-third as likely to hold a competitive job. Surprisingly, those with a chronic or acute medical condition were more likely to achieve competitive employment than those with other or no comorbidities. As before, study condition was significant in all four models with the advantage in competitive employment going to experimental group subjects.

In the fourth set of columns, which shows the likelihood of workplace disclosure of the participant's psychiatric 
disability, individuals with comorbidities affecting both physical and cognitive functioning were more than twice as likely to disclose. In addition, individuals with learning disabilities were more than three times as likely to disclose. Finally, this dependent variable was the only one not significantly influenced by study condition.

\section{DISCUSSION}

The results of this study point to the important influence of comorbidities on some but not all work outcomes among individuals receiving EBP supported employment. Those with any comorbidities had lower total earnings, worked fewer hours, and were less likely to work competitively than those with no comorbidity. Comorbidities affecting physical functioning were associated with lower earnings, fewer hours worked, and lower likelihood of competitive employment. Workplace disclosure of psychiatric disability was more likely among those with comorbidities affecting both physical and cognitive functioning and among those with learning disability. Competitive employment was less likely among those with any intellectual disability, visual impairment, and HIV/ AIDS. However, number of comorbidities was not significantly associated with any of the outcomes, and chronic and acute medical conditions were associated with a greater likelihood of competitive employment. These results substantially, though not uniformly, support the study's first hypothesis.

Study condition was also significant in three of four models, partially confirming the study's second hypothesis. The exception was the outcome of disclosure. A significant association with study condition may have been absent because disclosure is more a measure of workplace interpersonal environment than an indicator of vocational performance. Moreover, the high frequency of disclosure in both conditions (71\% and $75 \%)$ indicates that disclosure may be a common feature of returning to work for people with psychiatric disabilities, irrespective of vocational rehabilitation model. For the other three vocational outcomes, regardless of the presence, number, or type of comorbidities, participants receiving EBP supported employment had superior outcomes to those receiving "as usual," or comparison, services over the 24month study period.

\section{Study Limitations}

One limitation to the study's methodology is that recording and coding comorbidities may have varied across sites and researchers, possibly diluting the effect of the independent variables. Another limitation is that comorbidities were coded only at study baseline and so some conditions could have been missed if they developed during the study's follow-up period. The charts could also have contained erroneous diagnoses, included diagnoses that were no longer accurate at the time of data collection, or omitted diagnoses that were present. Because we did not code whether comorbidities were accompanied by functional limitations or whether they were being treated and controlled, we cannot assume that every co-occurring condition was severe enough to have vocational implications. Because we included both lifetime and current diagnoses of substance use disorders, we cannot specify whether abuse or dependence was active during the data collection period. At the same time, every approach to operationalizing comorbidities has its drawbacks. For example, respondent self-report is marred by problems of respondent recall, reluctance to report certain conditions, failure to recognize names of conditions, and only a small list of preselected conditions being queried [45-46]. Using Medicaid claims data to document comorbidities presents problems of only capturing treated conditions on paid claims [47]. While not ideal, our methodology has been used in other studies of this population and successfully identified a large number and range of co-occurring conditions [48]. Another limitation to the present analysis is that it focused primarily on medical and cognitive comorbidities rather than exclusively on co-occurring Axis I psychiatric diagnoses. The topic of psychiatric comorbidities is complex, worthy of a separate analysis. However, we believe it bears noting that unexamined psychiatric comorbidities may have important influences on the outcomes examined in the current article. Another study limitation is that the cohort studied in this analysis was not a nationally representative group of individuals with severe mental illness, and therefore, results cannot necessarily be generalized to the general U.S. population.

\section{Implications of Study Findings}

Our findings regarding the absence of effects of substance abuse/dependence on vocational outcomes were not surprising, given that prior studies of individuals receiving return-to-work services reached similar 
conclusions [16-19]. In a logistic regression analysis of data from 275 individuals with psychiatric disabilities in three vocational rehabilitation programs, Rogers et al. found that current substance abuse did not predict employment status at 3, 6, or 12 months after program entry [19]. Similarly, Bell et al. found that substance abuse did not affect work participation in a study of 220 patients with schizophrenia or schizoaffective disorder receiving vocational rehabilitation services involving job placement [16]. Finally, Drebing et al. examined archival data from 25,480 adults in the Veterans Health Administration Compensated Work Therapy program and found that those with co-occurring substance abuse and psychiatric disorders had better work functioning, more participation in vocational rehabilitation, and greater likelihood of competitive employment than those with psychiatric disorders alone [18]. Thus, the present study's findings are consistent with prior research regarding individuals receiving different models of vocational rehabilitation services.

Study results point to the importance of tailoring EBP supported employment programs serving those with severe mental illness and co-occurring conditions. This need for tailoring may be especially acute among those with conditions related to physical impairment, those who earned less money, those who worked significantly fewer hours, those who were less likely to work competitively, and (when accompanied by cognitive impairment) those who were more likely to disclose their mental illness. Mental health rehabilitation programs are seldom equipped to serve individuals with physical impairments and often need to be adapted for those with physical disabilities such as hearing impairment [49], blindness [50], TBI [51], and SCI [52]. Administrative support can be essential to dealing with issues such as assuring architectural accessibility to individuals in wheelchairs and those with other special needs [52]. Consultation with experts in these disability areas is needed for identifying the programmatic changes required to serve clients more effectively and thus enhance return-to-work outcomes.

The important role of supported employment specialists is particularly evident here. These vocational staff must be sensitive to return-to-work issues that arise for individuals with different types of comorbidities, whether physical or cognitive disabilities or chronic or acute medical conditions [53]. In many cases, this sensitivity to issues requires that specialists develop trusting relationships with clients so clients feel more comfortable sharing the particular chal- lenges they encounter at work [54]. Other instances may call for close consultation with clients' medical doctors, whose expertise can aid the development of a holistic and integrative vocational rehabilitation process [55]. Sometimes, clients' needs must be met through interagency linkages [14], which may involve organizations with limited experience working with mental health issues, and thus require cross-training and a willingness to share expertise.

In addition to employment barriers, individuals with mental illness and comorbid conditions are likely to face a broad range of legal, financial, psychosocial, and behavioral difficulties [11,13,51-52]. These difficulties include problems establishing and maintaining independent living and community integration, such as finding accessible housing and arranging transportation, which employment specialists are called to address. Supported employment specialists need to understand the impact that employment income may have on their clients' personal financial situations, especially when increased earnings result in reduced access to healthcare and medications, personal care attendants, and assistive technology such as hearing aids and voice-activated computers. These specialists also need to understand the client's need to purchase and repair medical equipment such as wheelchairs and ventilators $[14,52]$. Since individuals returning to work after a period of disability tend to assume jobs in which they work far fewer hours for lower pay [56], reemployment may occur at levels that do not make up the difference in reduced cash benefits and curtailed access to associated medical assistance [57]. For this reason, specialists may pay close attention to benefits planning and assistance while coordinating financial resources that enable individuals with multiple conditions to become and remain employed.

\section{CONCLUSIONS}

Individuals with severe mental illness and co-occurring disorders have poorer employment outcomes than those without comorbidities, and their psychiatric status is more likely to be disclosed to others in the workplace. Even though EBP supported employment services are effective for this population, knowledge of these relative disadvantages can be used for the enhancement of services for people with comorbidities by the tailoring of existing models. Future studies should address the needs of people with cooccurring conditions and ways that supported employment can be adapted to promote their continued employment. 


\section{ACKNOWLEDGMENTS}

The EIDP is a multisite collaboration between eight research demonstration sites, a coordinating center, and the Federal CMHS of the Substance Abuse and Mental Health Services Administration (SAMHSA).

The views expressed herein do not necessarily reflect the policy or position of any Federal agency.

This material was based on work supported by Cooperative Agreement SM51820. Ongoing dissemination is funded by the U.S. Department of Education, National Institute on Disability and Rehabilitation Research, and SAMHSA/CMHS under Cooperative Agreement H133B050003B.

The authors have declared that no competing interests exist.

\section{REFERENCES}

1. Kaye HS. Disability watch. Vol. 2. Oakland (CA): Disability Rights Advocates; 2001.

2. Bond GR, Becker DR, Drake RE, Rapp CA, Meisler N, Lehman AF, Bell MD, Blyler CR. Implementing supported employment as an evidence-based practice. Psychiatr Serv. 2001;52(3):313-22. [PMID: 11239097]

3. Cook JA, Leff HS, Blyler CR, Gold PB, Goldberg RW, Mueser KT, Toprac MG, McFarlane WR, Shafer MS, Blankertz LE, Dudek K, Razzano LA, Grey DD, BurkeMiller J. Results of a multisite randomized trial of supported employment interventions for individuals with severe mental illness. Arch Gen Psychiatry. 2005;62(5): 505-12. [PMID: 15867103]

4. Cradock-O’Leary J, Young AS, Yano EM, Wang M, Lee ML. Use of general medical services by VA patients with psychiatric disorders. Psychiatr Serv. 2002;53(7):874-78. [PMID: 12096172]

5. Dixon LB, Goldberg RW, Lehman A, McNary S. The impact of health status on work, symptoms, and functional outcomes in severe mental illness. J Nerv Ment Dis. 2001; 189(1):17-23. [PMID: 11206660]

6. Dixon L, Postrado L, Delahanty J, Fischer PJ, Lehman A. The association of medical comorbidity in schizophrenia with poor physical and mental health. J Nerv Ment Dis. 1999;187(8):496-502. [PMID: 10463067]

7. Dickey B, Normand SL, Weiss RD, Drake RE, Azeni H. Medical morbidity, mental illness, and substance use disorders. Psychiatr Serv. 2002;53(7):861-67. [PMID: 12096170]

8. Jones DR, Macias C, Barreira PJ, Fisher WH, Hargreaves WA, Harding CM. Prevalence, severity, and co-occurrence of chronic physical health problems of persons with serious mental illness. Psychiatr Serv. 2004;55(11):1250-57. [PMID: 15534013]

9. Sokal J, Messias E, Dickerson FB, Kreyenbuhl J, Brown $\mathrm{CH}$, Goldberg RW, Dixon LB. Comorbidity of medical illnesses among adults with serious mental illness who are receiving community psychiatric services. J Nerv Ment Dis. 2004;192(6):421-27. [PMID: 15167405]

10. Epstein J. Serious mental illness and its co-occurrence with substance use disorders, 2002. Rockville (MD): Department of Health and Human Services, Substance Abuse and Mental Health Services Administration, Office of Applied Studies; 2004.

11. Goldberg RW, Lucksted A, McNary S, Gold JM, Dixon LB, Lehman AF. Correlates of long-term unemployment among inner-city adults with serious and persistent mental illness. Psychiatr Serv. 2001;52(11):101-3. [PMID: 11141538$]$

12. Pickett-Schenk SA, Cook JA, Jonikas JA, Banghart M. Business as usual: Work experiences of homeless persons with mental illness. Res Community Ment Health. 2004;13:63-69.

13. Bradford DW, Gaynes BN, Kim MM, Kaufman JS, Weinberger M. Can shelter-based interventions improve treatment engagement in homeless individuals with psychiatric and/or substance misuse disorders? A randomized controlled trial. Med Care. 2005;43(8):763-68. [PMID: 16034289]

14. Meisler N, Blankertz L, Santos AB, McKay C. Impact of assertive community treatment on homeless persons with co-occurring severe psychiatric and substance use disorders. Community Ment Health J. 1997;33(2):113-22.

[PMID: 9145253]

15. Swartz JA, Lurigio AJ, Goldstein P. Severe mental illness and substance use disorders among former Supplemental Security Income beneficiaries for drug addiction and alcoholism. Arch Gen Psychiatry. 2000;57(7):701-7. [PMID: 10891041]

16. Bell MD, Greig T, Gill P, Whelahan H, Bryson G. Work rehabilitation and patterns of substance use among persons with schizophrenia. Psychiatr Serv. 2002;53(1):63-69. [PMID: 11773651]

17. Brooks AJ, Penn PE. Comparing treatments for dual diagnosis: Twelve-step and self-management and recovery training. Am J Drug Alcohol Abuse. 2003;29(2):359-83. [PMID: 12765211]

18. Drebing CE, Fleitas R, Moore A, Krebs C, Van Ormer A, Penk W, Seibyl C, Rosenheck R. Patterns in work functioning and vocational rehabilitation associated with coexisting psychiatric and substance use disorders. Rehabil Couns Bull. 2002;46(1):5-14.

19. Rogers ES, Anthony WA, Cohen M, Davies RR. Prediction of vocational outcome based on clinical and demographic indicators among vocationally ready clients. Community Ment Health J. 1997;33(2):99-112. [PMID: 9145252] 
20. Kessler RC, Adler L, Barkley R, Biederman J, Conners CK, Demler O, Faraone SV, Greenhill LL, Howes MJ, Secnik K, Spencert T, Ustun TB, Walters EE, Zaslavsky AM. The prevalence and correlates of adult ADHD in the United States: Results from the National Comorbidity Survey Replication. Am J Psychiatry. 2006;163(4):716-23. [PMID: 16585449]

21. Jorge RE, Starkstein SE, Arndt S, Moser D, CrespoFacorro B, Robinson RG. Alcohol misuse and mood disorders following traumatic brain injury. Arch Gen Psychiatry. 2005;62(7):742-49. [PMID: 15997015]

22. Vitry-Henry L, Pénalba C, Béguinot I, Deschamps F. Relationships between work and HIV/AIDS status. Occup Med (Lond). 1999;49(2):115-16. [PMID: 10436564]

23. Arns PG, Martin DJ, Chernoff RA. Psychosocial needs of HIV-positive individuals seeking workforce re-entry. AIDS Care. 2004;16(3):377-86. [PMID: 15203430]

24. Meisler N, McKay CD, Benasutti R. An ACT program for co-occurring disorders. Psychiatr Serv. 1999;50(12):1640. [PMID: 10577892]

25. McGurk SR, Mueser KT. Cognitive functioning, symptoms, and work in supported employment: A review and heuristic model. Schizophr Res. 2004;70(2-3):147-74. [PMID: 15329293]

26. Sher L. Depression and alcoholism. QJM. 2004;97(4):237-40. [PMID: 15028854

27. Wolf LE. College students with ADHD and other hidden disabilities: Outcomes and interventions. Ann N Y Acad Sci. 2001;931:385-95. [PMID: 11462755]

28. Glozier N. Mental ill health and fitness for work. Occup Environ Med. 2002;59(10):714-20. [PMID: 12356935]

29. Hinshaw SP, Cicchetti D. Stigma and mental disorder: Conceptions of illness, public attitudes, personal disclosure, and social policy. Dev Psychopathol. 2000;12(4): 555-98. [PMID: 11202034]

30. Wahl OF. Mental health consumers' experience of stigma. Schizophr Bull. 1999;25(3):467-78. [PMID: 10478782]

31. Wahl OF. Telling is risky business: Mental health consumers confront stigma. New Brunswick (NJ): Rutgers University Press; 1999.

32. Cook JA, Carey MA, Razzano LA, Burke J, Blyer CR. The pioneer: The Employment Intervention Demonstration Program. New Dir Eval. 2002;94:31-44.

33. Kessler RC, Berglund PA, Walters EE, Leaf PJ, Kouzis AC, Bruce ML, Friedman RM, Grosser RC, Kennedy C, Kuehnel TG, Laska EM, Manderscheid RW, Narrow WE, Rosenheck RA, Schneier M. A methodology for estimating the 12-month prevalence of serious mental illness. In: Manderscheid RW, Henderson MJ, editors. Mental health, United States 1998. Washington (DC): U.S. Department of Health \& Human Services; 1998. p. 99-109.
34. Gordis L. Epidemiology. Philadelphia (PA): W. B. Saunders Co; 2000.

35. Wehman P, Kregel J. A supported work approach to competitive employment for individuals with moderate and severe handicaps. J Assoc Pers Sev Handicaps. 1985;10(1):3-11.

36. Drake RE, McHugo GJ, Bebout RR, Becker DR, Harris M, Bond GR, Quimby E. A randomized clinical trial of supported employment for inner-city patients with severe mental illness. Arch Gen Psychiatry. 1999;56(7):627-33. [PMID: 10401508]

37. Russert MG, Frey JL. The PACT vocational model: A step into the future. Psychol Rehabil J. 1991;14:7-18.

38. Anderson SB. We are not alone: Fountain House and the development of clubhouse culture. New York (NY): Fountain House; 1998.

39. Beard J. The rehabilitation services of Fountain House. In: Stein LI, Test MA, editors. Alternatives to mental hospital treatment. New York (NY): Plenum Press; 1978.

40. Havassy BE, Shopshire MS, Quigley LA. Effects of substance dependence on outcomes of patients in a randomized trial of two case management models. Psychiatr Serv. 2000;51(5):639-44. [PMID: 10783183]

41. Lehman AF, Goldberg RW, Dixon LB, McNary S, Postrado L, Hackman A, McDonnell K. Improving employment outcomes for persons with severe mental illnesses. Arch Gen Psychiatry. 2002;59(2):165-72. [PMID: 11825138]

42. American Psychiatric Association. Diagnostic and statistical manual of mental disorders. Washington (DC): American Psychiatric Association; 1994. p. 4.

43. Tsang H, Lam P, Ng B, Leung O. Predictors of employment outcomes for people with psychiatric disabilities: A review of the literature since the mid '80s. J Rehabil. 2000;66:19-25.

44. Cook JA, Lehman AF, Drake R, McFarlane WR, Gold PB, Leff HS, Blyler C, Toprac MG, Razzano LA, Burke-Miller JK, Blankertz L, Shafer M, Pickett-Schenk SA, Grey DD. Integration of psychiatric and vocational services: A multisite randomized, controlled trial of supported employment. Am J Psychiatry. 2005;162(10):1948-56. [PMID: 16199843]

45. Linet MS, Harlow SD, McLaughlin JK, McCaffrey LD. A comparison of interview data and medical records for previous medical conditions and surgery. J Clin Epidemiol. 1989;42(12):1207-13. [PMID: 2585011]

46. Katz JN, Chang LC, Sangha O, Fossel AH, Bates DW. Can comorbidity be measured by questionnaire rather than medical record review? Med Care. 1996;34(1):73-84.

[PMID: 8551813]

47. Humphries KH, Rankin JM, Carere RG, Buller CE, Kiely FM, Spinelli JJ. Co-morbidity data in outcomes research: Are clinical data derived from administrative databases a reliable alternative to chart review? J Clin Epidemiol. 2000; 53(4):343-49. [PMID: 10785564$]$ 
48. Kamara SG, Peterson PD, Dennis JL. Prevalence of physical illness among psychiatric inpatients who die of natural causes. Psychiatr Serv. 1998;49(6):788-93. [PMID: 9634158]

49. Cook JA, Graham K, Razzano L. Psychosocial rehabilitation of deaf persons with severe mental illness: A multivariate model of residential outcomes. Rehabil Psychol. 1993; 38(4):263.

50. Leddy JC. Special rehabilitation workshop helps improve functioning of blind psychiatric patients. Hosp Community Psychiatry. 1974;25(11):714. [PMID: 4415850]

51. Stambrook M, Moore AD, Peters LC, Zubek E, McBeath S, Friesen IC. Head injury and spinal cord injury: Differential effects on psychosocial functioning. J Clin Exp Neuropsychol. 1991;13(4):521-30. [PMID: 1918283]

52. Kline MS, Kenly NB, Antonowicz AJ. Administrative support is important for a successful psychosocial rehabilitation program in a public psychiatric hospital. Adm Policy Ment Health. 2002;30(1):75-77. [PMID: 12546257]
53. Schneider M. Achieving greater independence through assistive technology, job accommodation and supported employment. J Voc Rehabil. 1999;12(3):159-64.

54. Targett P, Wehman P, Young C. Return to work for persons with spinal cord injury: Designing work supports. NeuroRehabilitation. 2004;19(2):131-39. [PMID: 15201472]

55. Burns SM, Young LR, Maniss S. Predictors of employment and disability among people living with HIV/AIDS. Rehabil Psychol. 2006;51(2):127-34.

56. Schechter ES. Industry, occupation, and disability insurance beneficiary work return. Soc Secur Bull. 1999;62(1): 10-22. [PMID: 10489685]

57. Polak P, Warner R. The economic life of seriously mentally ill people in the community. Psychiatr Serv. 1996; 47(3):270-74. [PMID: 8820550]

Submitted for publication July 11, 2006. Accepted in revised form March 12, 2007. 